\title{
Interactive Open Access Publishing and Peer Review: The Effectiveness and Perspectives of Transparency and Self-Regulation in Scientific Communication and Evaluation
}

\author{
Ulrich Pöschl \\ Max Planck Institute for Chemistry, Mainz, Germany, \\ u.poschl@mpic.de
}

\begin{abstract}
The traditional forms of scientific publishing and peer review do not live up to the demands of efficient communication and quality assurance in today's highly diverse and rapidly evolving world of science. They need to be advanced by interactive and transparent forms of review, publication and discussion that are open to the scientific community and to the public.
\end{abstract}

The advantages of open access, public peer review and interactive discussion can be efficiently and flexibly combined with the strengths of traditional publishing and peer review. Since 2001 the viability of this approach is demonstrated by the highly successful interactive open access journal Atmospheric Chemistry and Physics ( $\underline{\mathrm{ACP}})$ and a growing number of sister journals of the European Geosciences Union (EGU) and Copernicus Publications.

The achievements and statistics of these journals and their publishers clearly prove both the scientific benefits and the financial sustainability of open access. Future perspectives are outlined with regard to critical rationalism, open societies and the global information commons.

Key Words: scientific quality assurance; open peer review; collaborative peer review; open peer commentary 


\section{Introduction}

The traditional ways of scientific publishing and peer review do not live up to the needs of efficient communication and quality assurance in today's highly diverse and rapidly developing world of science. Besides high profile cases of scientific fraud, science and society are facing a flood of carelessly prepared scientific papers that are locked away behind subscription barriers, dilute rather than enhance scientific knowledge, lead to a waste of resources and impede scientific and societal progress (Pöschl, 2004).

Open access to scientific research publications is desirable for many educational, economic and scientific reasons (David and Uhlir, 2005; European Commission/UNESCO, 2008), but one of its key advantages is often not recognised. Contrary to widespread misperceptions, open access is not a threat but an urgently needed opportunity for the improvement of scientific quality assurance (Bodenschatz and Pöschl, 2008; Pöschl and Koop, 2008; Pöschl, 2009a,b):

1. Open access is fully compatible with traditional peer review, and beyond that it enables interactive and transparent forms of review and discussion open to all interested members of the scientific community and the public (interactive open access peer review alias public, collaborative or community peer review).

2. Open access gives reviewers more information to work with, i.e., it provides unlimited access to relevant publications across different scientific disciplines and communities (interdisciplinary scientific discussion and quality assurance).

3. Open access facilitates the development and implementation of new metrics for the impact and quality of scientific publications (combination of citation, download/usage, commenting and ranking by various groups of readers and users, respectively). Moreover, open access helps to overcome the obsolete monopoly/oligopoly structures of citation counting which have been stifling innovation in scientific research, publishing and evaluation over decades.

As demonstrated below, the effects and advantages of open access public review and interactive discussion can be efficiently and flexibly combined with the strengths of traditional scientific publishing and peer review (Pöschl, $2009 \mathrm{a}, \mathrm{b}, \mathrm{c})$ 


\section{Interactive Open Access Publishing}

So far, the arguably most successful alternative to the closed peer review of traditional scientific journals is the 'interactive open access peer review' practised by the journal Atmospheric Chemistry and Physics ( $\underline{\mathrm{ACP}})$ and a growing number of interactive open access sister journals (Pöschl, 2009a,b).

As detailed below (Sect. 3), ACP is by most if not all standards (editorial statistics, publication statistics, citation statistics, economic costs and sustainability) more successful than comparable scientific journals with traditional or alternative forms of peer review. The interactive open access peer review of ACP is based on a two-stage process of publication and peer review combined with interactive public discussion as illustrated in Figure 1.

In the first stage, manuscripts that pass a rapid pre-screening (access review) are immediately published as 'discussion papers' in the journal's discussion

Fig. 1: Interactive open access publishing with a two-stage publication process, public peer review and interactive discussion ('collaborative peer review') as practised in the scientific journal Atmospheric Chemistry and Physics (ACP) and its discussion forum Atmospheric Chemistry and Physics Discussions (ACPD).

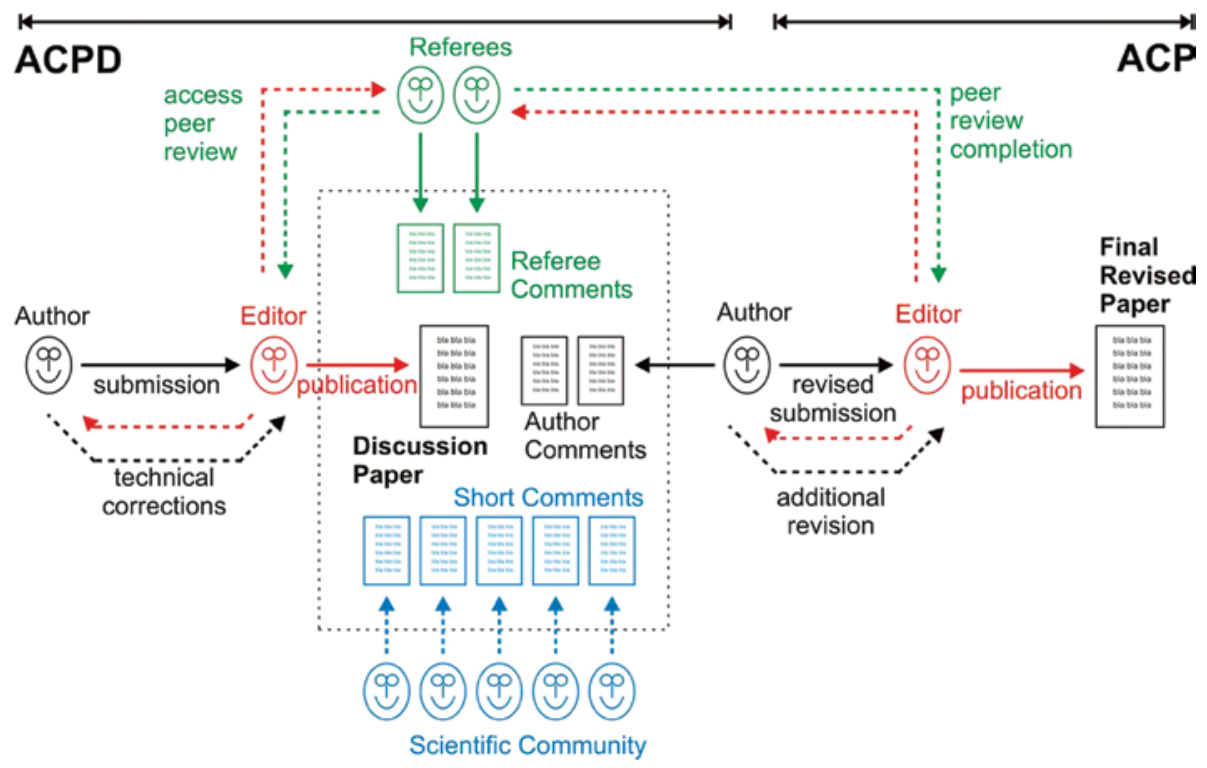


forum (Atmospheric Chemistry and Physics Discussions, ACPD). They are then subject to interactive public discussion for a period of eight weeks, during which the comments of designated referees, additional comments by other interested members of the scientific community, and the authors' replies are also published alongside the discussion paper. While referees can choose to sign their comments or remain anonymous, comments by other scientists (registered readers) are automatically signed. In the second stage, manuscript revision and peer review are completed in the same way as in traditional journals (with further rounds of review and revision where required) and, if accepted, final papers are published in the main journal. To provide a lasting record of review and to secure the authors' publication precedence, every discussion paper and interactive comment remains permanently archived and individually citable.

The interactive open access peer review and two-stage publication process of $\mathrm{ACP}$ effectively resolves the dilemma between rapid scientific exchange and thorough quality assurance, and it offers a win-win situation for all involved parties (authors, referees, editors, publishers, readers/scientific community). The primary positive effects and advantages compared to the traditional forms of publication with closed peer review are:

1. The discussion papers offer free speech and rapid dissemination of novel results and original opinions, without revisions that might delay or dilute innovation (authors' and readers' advantage).

2. The interactive peer review and public discussion offer direct feedback and public recognition for high-quality papers (authors' advantage); they prevent or minimise the opportunity for hidden obstruction and plagiarism (authors' advantage); they provide complete and citable documentation of critical comments, controversial arguments, scientific flaws and complementary information (referees' and readers' advantage); they reveal deficiencies and deter submissions of carelessly prepared manuscripts, thus helping to avoid/minimise the waste of time and effort for deficient submissions (referees', editors', publishers' and readers' advantage).

3. The final revised papers offer a maximum of scientific information density and quality assurance achieved by full peer review (with optional anonymity of referees) and revisions based on the referees' comments plus additional comments from other interested scientists (readers' advantage). 
Readers who are primarily interested in the quintessence of manuscripts that have been fully peer reviewed and approved by referees and editors can simply focus on the final revised paper (or, indeed, its abstract) published in the journal and neglect the preceding discussion papers and interactive comments published in the discussion forum. Thus the two-stage publication process does not inflate the amount of time required to maintain an overview of final revised papers. On the other hand, readers who want to see original scientific manuscripts and messages before they are influenced by peer review and revision, and who want to follow the scientific discussion between authors, referees and other interested scientists, can browse the papers and interactive comments in the discussion forum.

The possibility of comparing a final revised paper with the preceding discussion paper and following the interactive peer review and public discussion also facilitates the evaluation of individual publications for non-specialist readers and evaluators. The style and quality of interactive commenting and argumentation provide insights that go beyond, and complement, the information contained in the research article itself.

The two-stage publication process stimulates scientists to prove their competence via individual high-quality papers and their discussion, rather than just by pushing as many papers as possible through journals with closed peer review and no direct public feedback and recognition for their work. Authors have a much stronger incentive to maximise the quality of their manuscripts prior to submission for peer review and publication, since experimental weaknesses, erroneous interpretations, and relevant but unreferenced earlier studies are more likely to be detected and pointed out in the course of interactive peer review and discussion open to the public and all colleagues with related research interests.

Moreover, the transparent review process prevents authors from abusing the peer review process by delegating some of their own tasks and responsibilities to the referees during review and revision behind the scenes. Referees often make substantial contributions to the quality of scientific papers, but in traditional closed peer review their input rarely receives public recognition. The full credit for the quality of a paper published in a traditional journal generally goes to the authors, even when they have submitted a carelessly prepared manuscript that has taken a lot of time and effort on the part of the referees, editors and publishers to turn it into a good one. While peer review 
depends crucially on the availability and performance of referees, it has traditionally offered little reward for those providing careful and constructive reviews. In public review, however, referees' arguments are publicly heard and, if comments are openly signed, referees can also claim authorship for their contribution.

Note that most of the effects and advantages outlined above are not fully captured by alternative approaches where interactive commenting and public discussion occur only after formal peer review and final publication of scientific papers or where the discussion paper and interactive comments are removed after publication of the final revised paper (Sect. 5).

Overall, the interactive open access publishing philosophy emphasises the value of free speech and efficient public exchange and scrutiny of scientific results in line with the principles of critical rationalism and open societies. Accordingly, editors and referees are supposed to critically comment and evaluate manuscripts, to help authors improve their manuscripts, and to eliminate clearly deficient manuscripts. However, authors shall not be forced to adopt the editors' or referees' views and preferences. Instead, the readers shall be able to make up their own mind in view of the public review and discussion. In case of doubt, editorial decisions shall favour free speech of scientists, and in the end, scientific progress; history shall tell if — or to which degree - they were right. In scientific research, the line between fundamental flaws and major innovations can be fine, and the two-stage process of interactive open access publishing and peer review enables efficient balancing and differentiation between potentially misleading hypotheses and innovative theories even in highly controversial cases (Pöschl, 2004; 2009c).

\section{Atmospheric Chemistry and Physics}

The interactive open access journal Atmospheric Chemistry and Physics ( $\underline{\mathrm{ACP}})$, founded in 2001, demonstrates that interactive open access peer review enables much more efficient quality assurance than traditional closed peer review. ACP is run by the European Geosciences Union (EGU), the open access publisher Copernicus, and a globally distributed network of scientists ( 100 co-editors coordinated by an executive committee of five). Manuscripts are normally handled by an editor who is familiar with the specific subject area of the submitted work and independently guides the review process. 
Details about the largely automated handling and editor-assignment of submitted manuscripts are given on the journal website.

Currently ACP publishes about 700 papers per year (ca. 10,000 doublecolumn print pages), which is comparable to the volume of traditional major journals in the fields of chemistry and physics (ISI Science Citation Index). On average, each paper receives $4-5$ interactive comments, and about 1 in 4 papers receives a comment from the scientific community in addition to the comments from designated referees. In total, there are typically 0.5 pages of interactive comments per page of original discussion paper, i.e., the volume of interactive comments amount to as much as ca. $50 \%$ of the volume of discussion papers. The interactive comments show the full spectrum of opinions in the scientific community, ranging from harsh criticism to open applause (sometimes for the same discussion paper), and they provide a wealth of additional information and evaluation that is available to everyone.

About three out of four referee comments are posted without the referee's name, showing that most referees in the scientific community of ACP prefer anonymity. There are, however, interesting differences between sub-disciplines: on average about $40 \%$ of theoreticians and computer modelers sign their referee comments, while only $10 \%$ of the laboratory and field experimentalists do so. It appears that modelers more often provide suggestions and ideas for which they like to claim authorship as a reward. The anonymous referee comments are generally also very constructive and substantial. The ACP editors do no actively moderate the public discussions but reserve the right to delete abusive or inappropriately worded comments. Out of the nearly 10,000 interactive comments that have been posted so far, only a handful were removed or replaced because of inappropriate wording, which demonstrates efficient self-regulation by transparency.

Some colleagues have expressed concerns that referees may lose their independence by having access to the comments from fellow referees and from the public. Indeed, referees with limited capacities occasionally seem to duplicate or refer to earlier comments without making up their own mind, but this is fairly easy to recognise and to take into account by editors and readers. Much more often, however, referees constructively build on or contradict earlier comments, which enhances the efficiency of review and discussion substantially. Overall, experience shows that the advan- 
tages of enabling direct interaction between referees clearly outweigh the disadvantages.

The average rate of public commenting in addition to the designated referees' and authors' comments specified above (ca. 25\%) may appear low at first sight. It is, however, by an order of magnitude (factor ca. 10) higher than in journals with post-peer-review online commenting and in traditional journals without online commenting (about 1-2\%) (Müller, 2008; Pöschl and Koop, 2008; Pöschl, 2009a,b). Discussion papers reporting controversial findings or innovations attract many interactive comments (up to 30 and more, see 'Most commented papers' in the ACPD online library. As expected, non-controversial papers usually elicit comments only from the designated referees. Why would scientists invest effort and time commenting on papers which they find interesting but not controversial?

In most scientific disciplines and journals (certainly in the fields of physics, chemistry and biology with which the author is well acquainted) it is notoriously difficult to assign a couple of competent referees to every manuscript submitted for publication. In fact, this is the main bottleneck of peer review and scientific quality assurance, and most journal editors have to apply lots of manpower and electronic tools (invitation and reminder emails, etc.) to obtain a couple of referee comments per manuscript. Accordingly, the initiators and editors of ACP are quite satisfied with the overall number and volume of interactive comments. Higher rates of commenting were not expected and are not required to stimulate self-regulation mechanisms of scientific quality assurance (Pöschl, 2004; 2009a,b).

The editorial and citation statistics of ACP clearly demonstrate that interactive open access peer review indeed facilitates and enhances scientific communication and quality assurance. The journal has relatively low rejection rates (10-20\% as opposed to 50-60\% in comparable traditional journals (Schultz, 2009)), but only a few years after its launch ACP had already achieved top reputation and visibility in the scientific community. Accordingly, it quickly reached and maintained one of the highest ISI impact factors of several hundred journals indexed across the disciplines of atmospheric sciences, geosciences and environmental sciences (five citations per paper and year). These figures clearly confirm that anticipation of public peer review and discussion deters authors from submitting low-quality manuscripts and, thus, relieves editors and referees from spending too much time on deficient submissions. 
This is particularly important, because refereeing capacities are the most limited resource in scientific publishing and quality assurance.

Since its launch in 2001, the number of articles published in ACP has increased rapidly at growth rates around $20-50 \%$ per year, and the same is true for most interactive open access sister journals. The high and increasing rates of submission, publication and citation show that the scientific community values the open access, high quality and interactive discussions of ACP. They confirm that there is a demand for improved scientific publishing and quality assurance, and that the interactive open access journal concept of ACP meets this demand.

Accordingly, the EGU and Copernicus have launched and are operating a dozen of interactive open access sister journals in the geosciences and related disciplines, and more are in the pipeline ${ }^{1}$ :

- Atmospheric Chemistry and Physicss (ACP),

- Atmospheric Measurement Techniques (AMT),

- Biogeosciences (BG),

- Climate of the Past (ㅍ),

- Drinking Water Engineering and Science (DWES),

- Earth System Science Data (ESSD),

- Geoscientific Model Development (GMD),

- Hydrology and Earth System Sciences (HESS),

- Ocean Science (OS),

- Solid Earth ( $\underline{\mathrm{SE}})$,



- The Cryosphere (TC).

Note that the journal Hydrology and Earth System Sciences (HESS) had already existed as a subscription-based journal with traditional peer review before it was converted into an interactive open access journal. Soon after the transition, the journal experienced a substantial increase of submissions, publications and citations, demonstrating that traditional journals can be successfully converted into interactive open access journals.

The interactive open peer review concept of ACP has also been adopted by the e-journal economics, which was launched in 2007 and involves some of the most prominent institutions and scientists in the field of economics. 
Alternative concepts of public peer review and interactive discussion are pursued by the open access publications $\lfloor$ AMES (since 2008), PLoS One (since 2007), Biology Direct (since 2006), and IIME (since 1996). Differences between the peer review concepts of these publications and ACP will be addressed and discussed below (Sect. 5). In short, approaches where interactive commenting and public discussion are not fully integrated with formal peer review by designated referees tend to be less successful.

\section{Financing and Sustainability of Interactive Open Access Publishing}

$\mathrm{ACP}$ and its EGU/Copernicus sister journals prove not only the scientific but also the economic viability and sustainability of interactive open access publishing and peer review. The journals were launched and are operated by the independent scientific society EGU and by the small commercial enterprise Copernicus without public subsidies, private donations, or venture capital as involved in the start-up and operation of other successful open access publishers like PLoS and BioMed Central. After several years of operation, $\mathrm{ACP}$ and its sister journals have recovered the financial investments of EGU and Copernicus during the start-up phase, and they now deliver a surplus which supports the start-up of new journals by the scientific society as well as a healthy growth of the commercial publisher generating dozens of new jobs.

By developing and applying efficient software tools for the handling of manuscripts (submission, peer review and commenting, typesetting/production and distribution), and because minimal time and effort is wasted on carelessly prepared papers (high quality of submissions and low rejection rates as detailed above), Copernicus is able to produce top quality publications at comparatively low cost. The service charges for an average paper (about 10 pages in the final double column format) are about 1,000 EUR, covering editorial support, free use of colour figures and online supplementary materials (data, pictures, movies etc.), typesetting of both the discussion and the final version of the paper, archiving and distribution of papers and interactive comments (maintenance of websites and servers, electronic copies for open archives, paper copies for copyright libraries, etc.) and overheads. The service charges are adjusted to cover the full costs of publishing, including all the tasks and services outlined above, and generate a modest surplus (ca. $10 \%$ ) that ensures sustainability of Copernicus, EGU, and their publications. 
For each paper published in ACP, the service charges are levied from the authors or paid by their scientific institution. Since 2008 the German Max Planck Society (MPG) and the French Centre National de Recherche Scientifique ( $\underline{\mathrm{CNRS}}$ ) have contracts with Copernicus for automated coverage of service charges incurred by their scientists. Other scientific institutions are likely to follow these examples, and many national and international research organisations and funding agencies pursue complementary ways of covering open access service charges for their scientists and projects. Like other open access publishers, Copernicus and EGU are ready to cover the costs for up to $10 \%$ of the papers published each year, if the authors are unable to pay the service charges (e.g., authors without institutional support or institutions from less developed countries). Currently, most papers published in ACP originate from Europe (ca. 60\%) and North America (ca. 30\%), but the proportion of papers originating from Asia and other regions is increasing.

The ACP open access publication service charges compare quite favourably with the charges levied by other comparable scientific journals and publications:

1. Other major open access publishers such as BioMed Central and the Public Library of Science (PLoS) typically charge more than 1,000 EUR for traditional single-stage journal publications.

2. Traditional publishing groups like Springer charge 2,000 EUR for making individual publications in traditional subscription journals freely available online ('open choice'), i.e., they levy 2,000 EUR per online open access paper in addition to charging libraries and other subscribers for access to the journal in which it appears.

3. In the traditional scientific publishing business, where some journals do not only limit access to subscribers or sell articles on a pay-per-view basis but also request additional publication charges from authors (up to several hundred US dollars per page or colour figure), the total turnover and public costs amount to several thousand US dollars per paper. The annual turnover of journal publishing in the sector of science, technology, and medicine (STM) amounts to around 7 billion USD per year, and some of the traditional publishers - led by Elsevier with a market share of about $30 \%$ - make operating profits of up to $30 \%$ and more. Note that a large proportion of the turnover and profit in STM publishing comes from packaging and selling publicly funded research results that are peer reviewed by publicly funded scientists to publicly funded institutions of education and research. 
In view of these facts, $\mathrm{ACP}$ authors and the $\mathrm{ACP}$ scientific community have had little difficulty in accepting and paying average service charges of about 1,000 EUR per paper to make ACP and its sister journals sustainable. Overall, $\mathrm{ACP}$ and its interactive open access sister journals prove that top quality (interactive) open access publishing and peer review can be realised and sustained by scientific societies and (small) commercial publishers with tightly limited budgets and without public subsidies, private donations or venture capital. Indeed, ACP, EGU and Copernicus demonstrate how STM publishing at large can and will hopefully soon manage a swift transition from the past of printbased subscription barriers into the future of internet-based open access.

\section{Key Features of Interactive Open Access Peer Review Compared to Alternative Forms of Closed or Open Peer Review}

To summarise, the key features of the ACP interactive open access peer review system that help ensure maximum efficiency of scientific exchange and quality assurance are:

1. Publication of discussion papers before full peer review and revision: free speech, rapid publication, and public accountability of authors for their original manuscript foster innovation and deter careless submissions.

2. Integration of public peer review and interactive discussion prior to final publication: attract more comments than post-peer-review commenting, enhance efficiency and transparency of quality assurance, maximise information density of final papers.

3. Optional anonymity for designated referees: enables critical comments and questions by referees who might be reluctant to risk appearing ignorant or disrespectful.

4. Archiving, public accessibility and citability of every discussion paper and interactive comment: ensure documentation of controversial scientific innovations or flaws, public recognition of commentators' contributions, and deterrence of careless submissions.

Combining all of the above features and effects is the basis for the great success of ACP and its sister journals. Missing out on one or more of these features is the main reason why most if not all alternative forms of peer review 
practised in other initiatives for improving scientific communication and quality assurance have been less successful (less commenting, lower impact/ visibility, higher rejection rates, larger waste of refereeing capacities, etc.). For example, features 2 and 3 are not captured in most of the initiatives mentioned at the end of Sect. 3.

For several reasons also the 'open peer review trial' of the Nature magazine in 2006 was not a good example and measure for the engagement of scientists in interactive commenting and public peer review on the internet. In that experiment, neither the authors of an article nor their colleagues and readers had much of an incentive to participate in the public discussion. The authors had to accept that their article was exposed in parallel to public scrutiny as well as to a closed peer review process where the referee comments remain nonpublic and where most of submitted manuscripts are rejected not because of a lack of scientific quality but because they are not deemed sufficiently exciting for the interdisciplinary audience of the magazine (ca. 93\% rejection rate $)^{2}$. For the likely outcome that a manuscript would not pass the closed peer review, it was not clear whether and in which form the rejected manuscript and the public comments would remain publicly accessible. As one might have imagined beforehand, this is not a very attractive perspective for scientists trying to get recognition for their most exciting results. Similarly, colleagues and readers had little incentive to formulate and post substantial comments, because their contributions would just have been an addendum to the closed peer review proceeding in parallel and would likely disappear afterwards. Fortunately, the publishers of Nature seem to have realised that permanent archiving and citability are key features of scientific exchange, and they have launched a more promising initiative titled Nature Precedings. There manuscripts can be published, openly discussed and archived in a similar way as in the discussion forums of interactive open access journals ${ }^{3}$.

Unfortunately, however, it seems that the paramount importance of archiving and citability of manuscripts and comments has not yet been fully recognised by scientific publishers and societies. Following up on the success and leadership of the EGU in interactive open access publishing and peer review, the American Geophysical Union (AGU) has recently also started an experiment with 'open peer review'. Instead of building on the very positive experience and success of the European sister society, however, AGU seems to follow the tracks of the unsuccessful earlier trial of Nature. Specifically, AGU announced that the discussion paper and all interactive comments shall be deleted after 
completion of the peer review process and final acceptance or rejection of the revised manuscript (Albarede, 2009). If AGU were to continue this approach, they would largely miss out on the effects detailed under point 4 above, and it appears questionable that the perspective of deletion after a couple of months will attract substantial commenting from the scientific community. Hopefully, the proponents of the AGU experiment will realise that the deletion of scientific comments is not only a discouragement for potential commentators but also a regrettable underestimation of the value of scientific discussion and discourse in the history and progress of science.

Experience and rational thinking suggest that interactive open access peer review should be applicable and beneficial for journal publications in most if not all disciplines of scientific research (STM as well as social sciences, economics and humanities). For consistency and traceability, discussion papers and interactive comments should generally remain archived and citable as published, and they should be regarded as proceedings-type publications. Due to the proceedings character of discussion papers, the authors of revised manuscripts that may not have been accepted for final publication in the interactive open access journal to which they had originally been submitted can still pursue review and publication in alternative journals. As indicated above, such aspects are particularly important with regard to highlight magazines or journals in which the review process is not only aimed at ensuring scientific quality but also at high selectivity with regard to interdisciplinary relevance and visibility, which entails low probability of acceptance even for manuscripts of high quality (see Nature trial).

In addition to the above general features, the following specific procedural aspects have turned out to be important for the practical implementation and effectiveness of interactive open access publishing and peer review:

1. Editor assignment: For the assignment of a newly submitted manuscript to a handling editor, the online editorial office automatically sends invitation letters to all co-editors covering the relevant subject area (based on index terms selected by authors). Depending on competence and availability, each co-editor can then decide if s/he wants to take editorship (first come, first served). If no handling editor can be found via the automated assignment process, the authors and the executive authors are informed and asked to directly contact individual co-editors if they are ready to take editorship. Note that this sec- 
ond line of editor assignment in ACP is similar to the editor assignment procedure in the open access journal Biology Direct $t^{4}$. There it is up to the authors to find and motivate an editorial board member to guide the review process for their paper, and the manuscript is effectively rejected if none of the board members agree.

2. Access review: Prior to publication in the discussion forum, the editor is asked to evaluate whether the submitted manuscript is within the scope of the journal and whether it meets basic quality criteria. If necessary, the editor may consult referees for a rapid and preliminary initial rating of the manuscript ${ }^{5}$. The editor or referees can request/ suggest minor technical corrections and adjustment (typing errors, clarifications, etc.). Further requests for revision of the scientific contents are not allowed at this stage of the review process but shall be expressed in the interactive discussion following publication of the discussion paper. For rapid processing and in order to save refereeing capacities the editor shall normally perform the access review without the referees, unless their advice is urgently needed or the authors have requested their involvement. In a statement or cover letter accompanying the submitted manuscript, the authors can indicate if they have any preference with regard to involving the referees already in the access review. Obviously, the involvement of referees can lead to delays, but on the other hand the authors may want to receive a preliminary rating and suggestions for minor corrections prior to publication of the discussion paper.

3. Final response and review completion: In the final response phase at the end of the interactive public discussion, the authors shall respond to all comments. The editor has the opportunity to add comments and suggestions, but normally editorial decisions and recommendations should not be taken and expressed before the authors have responded to all comments ('audiatur et altera pars'). Instead, it shall be up to the authors to decide if they want to pursue final publication and how they shall revise their manuscript in view of the public review and discussion (self-regulation once again). Depending on the situation, they can but need not ask and wait for the editor to give advice on how to proceed and whether a revised version is likely to be accepted for final publication. After receiving critical feedback, mature and responsible scientists should normally know best how to revise their manuscript. Indeed, the improvements upon revision of a manuscript after public discussion often go far beyond the requests 
and suggestions expressed by the referees. Premature interference by the editor would likely reduce rather than enhance the authors' motivation for improving the manuscript upon revision. Moreover, premature editorial recommendations published by the editor before seeing the authors' final response and the revised manuscript could potentially bias the final decision about acceptance or rejection.

After receiving the revised manuscript the editor has a complete picture, can check if all comments and suggestions have been properly taken into account, and can suggest or request further improvements. If required, the process of review and revision can be iterated with the help of referees. So far, such iterations of peer review as well as appeal procedures in case of controversial editorial decisions have not been handled in public to avoid unnecessary complications. In the end, however, the discussion forum can and shall be used to explain editorial decisions in a rational and transparent way as illustrated by an example from Atmos. Chem. Phys. Discuss. (Pöschl, $2009 c)^{6}$.

\section{Conclusions and Future Perspectives}

$\mathrm{ACP}$ and its sister journals very clearly demonstrate that interactive open access peer review with a two-stage publication process and public discussion effectively resolves the dilemma between rapid scientific exchange and thorough quality assurance. They have proven that interactive open access peer review indeed fosters scientific discussion, deters submission of sub-standard manuscripts, saves refereeing capacities, and enhances information density in final papers. Moreover, ACP, EGU and Copernicus prove the financial sustainability of open access publishing, and they may serve as a role model for how STM publishing at large can manage the transition from the past of print-based subscription barriers into the future of internet-based open access. The key for a successful, smooth, and efficient transition is to utilise the opportunities of modern technology and interactivity while maintaining the strengths of traditional structures and procedures.

Interactive open access peer review easily can be integrated into new and existing scientific journals as well as large-scale publishing systems and repositories such as arXiv.org - simply by adding an interactive discussion 
forum. Equipped with appropriate interactive commenting tools, a large repository such as arXiv.org could not only serve as an archive for 'preprints' or 'e-prints', but also as a platform for efficient review and discussion, where authors could post their discussion papers and different journals could send their referees for public review. Similarly, individual publishers could set up central discussion forums to serve different journals or journal sections. Depending on the outcome of public review and discussion, the revised manuscripts could then be sorted and grouped at different levels of relevance for different audiences - analogous to the quality ranking system and tiers of the Berkeley Electronic Press journals in economics ${ }^{7}$.

For interdisciplinary highlight papers, EGU and Copernicus are currently preparing the introduction of a third stage of interactive open access publishing that shall lead to efficient grouping of scientific publications in three tiers with the following characteristics:

1. Discussion forum (discussion papers \& interactive comments):

- free speech (for authors \& scientific community)

- original opinions

- immediate publication and dissemination

2. Topical journal (final papers):

- thorough quality assurance (collaborative peer review)

- comprehensive, complete and validated information

3. Highlight magazine (abstracts):

- highly condensed information

- interdisciplinary relevance \& public interest

- three-stage selection process (distillation).

The interactive open access highlight magazine shall be dedicated to the selection and presentation of the abstracts of highlight papers, which outline the forefront of research and are of high interdisciplinary relevance and public interest. The editorial board of the magazine shall select highlight papers that have undergone public peer review and discussion in topical open access journals, and the abstracts of the highlight papers shall be commented and compiled with direct references and links to the original papers and journals, respectively. By building on rather than competing with topical scientific journals, the highlight selection process and magazine shall provide high efficiency, conciseness and interdisciplinarity without compromising scientific completeness and quality assurance. This might also be a way forward for 
traditional highlight magazines like Nature or Science covering the full width of scientific disciplines.

The basic concepts of interactive open access publishing and peer review can be easily adjusted to the different needs and capacities of different scientific communities by maintaining or abandoning referee anonymity, shortening or prolonging the public discussion phase, adding post-peer-review commenting and rating tools for readers, making all steps/iterations of peer-review and revision transparent, adding further stages of publication for re-revised manuscripts, establishing feedback loops for editorial quality assurance, etc.

Besides communication and evaluation of scientific results, interactive open access peer review might also be applicable for efficient evaluation of scientific research proposals in the form of citable discussion papers. Again all involved parties could profit from public documentation, scrutiny and citability. At first sight, it might appear that the authors of a proposal would run a high risk of 'losing' innovative project ideas to the public. In practise, however, they might be better protected from (hidden) plagiarism and obstruction by competitors, and the citable publication might actually help them to claim authorship, precedence and recognition for their ideas. At the same time, the scientific community and society at large might profit from rapid dissemination of innovative ideas.

Overall, interactive open access publishing and peer review can strongly enhance scientific exchange and quality assurance. The concept has been very successfully applied and extended over the past decade, demonstrating both the scientific benefits and the financial sustainability of open access. It will likely emerge as a best practise model for the future of scientific publishing, and it provides a solid basis for efficient use and augmentation of scientific knowledge in the global information commons (David and Uhlir, 2005). Moreover, public review, discussion and documentation of the scientific discourse can serve as an example for rational and transparent procedures of settling complex questions, problems, and disputes. It is a model for further development of the structures, mechanisms, and processes of communication and decision making in society and politics in line with the principles of critical rationalism and open societies.

In order to realise the vision of improved communication and evaluation in the global information commons, I would like to renew the following prop- 
ositions and recommendations to scientists and scientific publishers, librarians, institutions, and funding agencies (Pöschl, 2004):

1. Promote open access to publicly funded research publications by appropriate guidelines and by moving funds from subscription budgets to publication budgets - preferably at high rates $(20 \%$ per year or more). Obviously, traditional publishers are reluctant to undermine their profits as long as they can rely on rigid subscription schemes, but the ones who are ready to serve science will swiftly adapt to new financing schemes as illustrated by the open choice model and acquisition of BioMedCentral by Springer ${ }^{8}$. The others can be substituted by new service providers as indicated by the swiftly growing number, size and visibility of open access publishers and journals 9 .

2. Promote interactive open access peer review in new and existing journals, repositories and other publication platforms. Public review and interactive discussion are technically straightforward and can be flexibly adjusted to different scientific communities, but care should be taken when dealing with key features of peer review and scientific discourse (optional anonymity for designated referees, permanent archiving and citability of published manuscripts and comments, etc.).

3. Promote the development and implementation of new and improved metrics for the impact and quality of scientific publications (combination of citation, download/usage, commenting and ranking by various groups of readers and users, respectively). Note that open access is urgently needed to stimulate innovation by competition in this field, which has long been hampered by monopoly structures. The working capacities of librarians and related information professionals that may be liberated by the end of the subscription business are urgently needed for the structuring, processing, quality assurance and digital preservation of scientific contents, bibliometric data and statistical analyses both at scientific institutions and at commercial service providers.

Thus, it appears timely and appropriate for all parties involved in scientific publishing and interested in scientific and societal progress to jointly pursue and achieve a swift transition from the subscription barriers of the past to the interactive open access environment of the future ${ }^{10}$. 


\section{References}

Albarede, F. (2009): 'AGU Announces Open Peer Review Experiment', EOS Trans. AGU, 90, 276, http://www.agu.org/pubs/crossref/2009/ 2009EO320005.shtml

Bodenschatz, E., and U. Pöschl (2008): 'Open Access and Quality Assurance', in: Open Access Challenges and Perspectives - A Handbook, European Commission and German Commission for UNESCO, http:/ / ec.europa.eu/research/science-society/ document library/pdf_06/open-access-handbook en.pdf

David, P.A., and P.F. Uhlir (2005): 'Creating the Information Commons for e-Science: Toward Institutional Policies and Guidelines for Action', Workshop Proceedings, UNESCO, Paris, http:// www.codata.org/archives/2005/ UNESCOmtg/agenda.html

European Commission and German Commission for UNESCO (2008): Open Access Opportunities and Challenges - A Handbook, http://ec.europa.eu/research/ science-society/document library/pdf 06/open-access-handbook en.pdf

Müller, U. (2008): Peer-Review-Verfahren zur Qualitätssicherung von OpenAccess-Zeitschriften - Systematische Klassifikation und empirische Untersuchung, $\mathrm{PhD}$ Thesis, Humboldt University, Berlin, http:/ / edoc.hu-berlin.de/dissertationen/ mueller-uwe-thomas-2008-12-17/PDF/mueller.pdf

Pöschl, U. (2004): 'Interactive journal concept for improved scientific publishing and quality assurance', Learned Publishing 17, p. 105-113, http:/ / www.atmosphericchemistry-and-physics.net/pr acp interactive journal concept.pdf, http://www. ingentaconnect.com/content/alpsp/lp/2004/00000017/00000002/art00005

Pöschl, U., and T. Koop (2008): 'Interactive open access publishing and collaborative peer review for improved scientific communication and quality assurance', Information Services \& Use 28 (Special Issue APE 2008: Academic Publishing in Europe, Quality and Publishing, IOS Press), p. 105-107, http://www.atmosphericchemistry-and-physics.net/pr acp poeschl koop infoservuse 2008 intoapub.pdf

Pöschl, U. (2009a): 'Interactive Open Access Peer Review: The Atmospheric Chemistry and Physics Model', Against the Grain 21, p. 26-34, http:// www.againstthe-grain.com/d/TOCIssue?\&volsearch=21\&issuesearch=3

Pöschl, U. (2009b): 'Interactive open access publishing and peer review: The effectiveness of transparency and self-regulation in scientific quality assurance', Proceedings of the World Library and Information Congress 2009 (75th IFLA General Assembly), Sect. 142, pp. 1-7, Milan, http://www.ifla. org/files/hq/papers/ifla75/142-poschl-en.pdf

Pöschl, U. (2009c): 'Interactive comment on "On the validity of representing hurricanes as Carnot heat engine" by A.M. Makarieva et al.', Atmos. Chem. 
Phys. Discuss. 8, S12406-S12411, http:// www.atmos-chem-phys-discuss. net/8/S12406/2009

Schultz, D.M. (2009): 'Rejection rates for journals publishing atmospheric science', Bulletin of the American Meteorological Society, submitted.

\section{Websites Referred to in the Text}

arXiv.org, http://arxiv.org/

Atmospheric Chemistry and Physics (ACP), www.atmos-chem-phys.net

Atmospheric Measurement Techniques (AMT), http://www.atmospheric-measurementtechniques.net

Biogeosciences (BG), http:/ / www.biogeosciences.net

Biology Direct, www.biology-direct.com

Centre National de Recherche Scientifique, http://www.insu.cnrs.fr/

Climate of the Past (CP), http:/ / www.climate-of-the-past.net

Copernicus Publications, www.copernicus.org

Drinking Water Engineering and Science (DWES), http://www.drinking-waterengineering-and-science.net)

Earth System Science Data (ESSD), http://www.earth-system-science-data.net

Economics, www.economics-ejournal.org

EGU, European Geosciences Union, www.egu.eu

Geoscientific Model Development (GMD), http://www.geoscientific-model-

development.net

Hydrology and Earth System Sciences (HESS), http://www.hydrology-and-earthsystem-sciences.net

JAMES, http://adv-model-earth-syst.org

$J I M E$, http://www-jime.open.ac.uk

Max Planck Society, http://www.mpg.de/

Most commented papers, ACPD online Library, www.atmos-chem-phys-discuss. net/most commented papers.html

Ocean Science (OS), http:/ / www.ocean-science.net 
PLoS One, www.plosone.org

Solid Earth (SE), http://www.solid-earth.net

Social Geography (SG), http:/ / www.social-geography.net

The Cryosphere (TC), http://www.the-cryosphere.net

\section{Acknowledgement}

U. Pöschl would like to thank P.J. Crutzen, T. Koop, K.S. Carslaw, R. Sander, W.T. Sturges, A.K. Richter, the scientific communities of ACP and EGU, and the team of Copernicus for their major contributions to the development of interactive open access publishing.

\section{Notes}

${ }^{1}$ http://publications.copernicus.org/open access journals/journals by subject.html

${ }^{2}$ www.nature.com/nature/peerreview/debate/nature05535.html

${ }^{3}$ http://precedings.nature.com/site/help

${ }^{4}$ http://www.biology-direct.com/info/about/

${ }^{5}$ http://www.atmospheric-chemistry-and-physics.net/review/ms evaluation criteria.html

${ }^{6}$ http://www.atmos-chem-phys-discuss.net/8/S12406/2009

${ }^{7}$ http://www.bepress.com/bejm, http://www.bepress.com/bejte

${ }^{8}$ http://www.springer.com/open+access

${ }^{9}$ http://www.oaspa.org/, http://www.doaj.org/

${ }^{10}$ Further information about interactive open access publishing is freely available on the internet: http://www.atmospheric-chemistry-and-physics.net/general information/public relations.html 